\title{
Remineralizing Agents in Dentistry: A Review
}

\author{
Dr Keerthi Venkatesan ${ }^{1}$, Dr Manish Ranjan ${ }^{2}$ \\ ${ }^{1}$ (Senior Lecturer, Department of Conservative Dentistry and Endodontics, Thai Moogambigai Dental College, \\ Chennai, India) \\ ${ }_{2}^{2}$ (Senior Lecturer, Department of Conservative Dentistry and Endodontics, Saveetha Dental College, \\ Chennai, India)
}

\begin{abstract}
Dental caries is an infectious microbiologic disease that results in destruction of calcified tissues. The routine drill and fill technique eliminates bacteria only at the site of restoration and recolonization can occur in remaining part of oral cavity. Present day treatment aims on conservation of tooth structure by identifying decalcification in earlier stages followed by treatment with remineralization. This paper discusses on various remineralization treatment options available and their mode of action.
\end{abstract}

Keywords: Casein phosphopeptide-amorphous calcium phosphate, Dental Caries, Fluorides, Remineralization, Ozone.

\section{Introduction}

The human tooth is composed of highly mineralized tissues of the body containing hydroxyapatite as the primary constituent.

Miller's "chemoparasitic theory" states that caries is brought about by acid dissolution of mineral phase of teeth, the acid being produced by metabolism of dietary carbohydrates by oral bacteria. This theory emphasizes that there is an association between mineral content of teeth and dental caries.

Dental hard tissues are continuously undergoing cycles of demineralization and remineralization. A drop in $\mathrm{pH}$ of oral cavity results in demineralization which if continued leads to loss of minerals from tooth structure resulting in dental caries. The reversal can occur if $\mathrm{pH}$ rises resulting in deposition of calcium, phosphate and fluoride $[1,2]$.

Dental caries is a dynamic process which occurs when demineralization exceeds remineralization. But progression of dental caries is a slow process and during early stages non-invasive intervention can convert the lesion to inactive state from an active state [3]. This principle is the key to preventive dentistry. The preventive approach of identification, conservative, non-restorative treatment of incipient caries saves both dental manpower for profession as well as expense and suffering for the patient.

Early diagnosis of incipient lesions can lead to new era in preventive dentistry in the form of remineralization. The best mode for caries management is use of remineralizing products. Presently fluoride, calcium phosphate-based systems, calcium sodium phosphosilicate, etc., that help in remineralization are available commercially. This article focuses on various remineralizing agents and their mode of action and clinical applications.

\section{Fluorides}

Fluorides are the most effective agent in prevention of dental caries. They are supplied in the form of dentifrices and rinses for personal use. Professionally, they are used in the form of varnishes, solutions, gels and fluoride releasing restorative materials. The mechanism of action of fluorides includes [4]:

- The fluoride ion can exchange with hydroxyl group in the apatite crystal forming fluorapatite which is more stable and less soluble crystal,

- The fluoride can enter void spaces on the apatite crystal and provide stability by additional bonds,

- Fluorides can contribute to remineralization of early lesions,

- Fluorides can act as an antimicrobial agent against bacteria and

- Inhibits enzymes essential to bacterial metabolism and growth [5].

Fluoride at optimal levels has a definite anticaries effect which is a boon to preventive dentistry.

\subsection{Personally used Fluorides}

\subsubsection{Fluoride Dentrifices and Mouthrinses [6]}

Dentrifices contain $0.1 \%$ fluoride and uptake of this fluoride in etched enamel or in incipient lesions enhances remineralization.

Fluoride mouthrinses are advised for school children over 5 years of age, person with high caries susceptibility and patients with orthodontic and prosthetic appliance. 


\subsection{Professionally applied Fluorides \\ 2.2.1 Fluoride Solutions [6]}

The topical solutions of fluoride used are $2 \%$ sodium fluoride, $8 \%$ stannous fluoride and $1.23 \%$ of acidulated phosphate fluoride solutions.

Initially a prophylaxis is done followed by drying and isolation of each quadrant and this $2 \%$ sodium fluoride is applied for 3-4 minutes. This procedure is called Knutson's technique which is done at 3, 7, 10 and 13 years. Calcium fluoride reservoir is formed in this technique.

$8 \% \mathrm{SnF}_{2}$ is applied for 2 minutes and when this solution reacts with enamel, tin phosphate, calcium fluoride and tin-fluoride-phosphate are formed.

$1.23 \%$ of acidulated phosphate fluoride solutions leads to demineralization of enamel and hence forms calcium fluoride and releases phosphate. Phosphate shifts the equilibrium leading to formation of hydroxyapatite and fluorapatite.

\subsubsection{Fluoride gels [6]}

Gels adhere to teeth and eliminate continuous wetting of enamel and it is possible to treat two-four quadrants simultaneously.

\subsubsection{Fluoride varnish [6]}

Topical fluoride reagents have the disadvantage of rapid loss of soluble fluoride formed on teeth. To combat this problem, waterproof sealant in the form of fluoride varnish was introduced [7]. This procedure improves reaction time between fluoride and enamel providing long term effect. Currently, sodium fluoride based varnish (Duraphat) and polyurethane based varnish (Fluorprotector) are commonly used.

\subsubsection{Fluoride Releasing Restorative Materials}

Glass ionomer cement releases fluoride which is found to be incorporated in enamel [8], cavity walls [9] and bacteria inhibiting acid production [10,11]. Further fluoride recharge ability of glass ionomer cement helps in long term inhibition of caries. The recharging ability of this cement fully depends on the hydrogel layer over glass filler. Initially glass ionomer cement releases fluoride which reduces over time wherein this released fluoride can be recharged with extrinsic fluoride [12] in the form of fluoride solution, varnish, fluoridated dentrifice [13] or fluoride mouthrinse.

Compomers consists of silicate glass particles, sodium fluoride and polyacid-modified monomer without any water. Compomers release less fluoride compared to glass and hybrid ionomers [14].

Giomers consists of pre-reacted glass ionomer particles and composites thus exhibiting properties of fluoride release and recharging with excellent aesthetics [15]. Giomers released more fluoride than compomer or composites [16].

Pit-and-fissure sealants contain strontium-fluoride-aluminosilicate glass as filler which undergoes hydrolysis and releases fluoride through external and internal diffusion [17].

\section{Calcium Phosphate Based Remineralization}

Four systems are based on calcium phosphate:

3.1 Enamelon ${ }^{\mathrm{TM}}$ is based on technology of unstabilized amorphous calcium phosphate with fluorides. This works on the principle that since calcium and phosphate ions are not stabilized thus allowing the two ions to combine into insoluble precipitates. These precipitates dissolve in saliva releasing amorphous calcium fluoride phosphate precipitates which in turn transforms to a more thermodynamically stable fluorhydroxyapatite. Calcium and phosphate ions henceforth transiently bioavailable promotes remineralization by inhibiting demineralization [18].

3.2 Recaldent ${ }^{\mathrm{TM}}$ is derived from casein, a protein derived from cow's milk. It is technically available as casein phosphopeptide stabilized amorphous calcium phosphate. This technology works when casein phosphopeptide binds to pellicle and plaques by stabilizing high concentrations of calcium and phosphate ions with fluorides at tooth surface. These ions can freely diffuse to enamel subsurface lesions to promote remineralization [18].

3.3 Bioactive glass is composed of $\mathrm{SiO}_{2}, \mathrm{Na}_{2} \mathrm{O}, \mathrm{CaO}$ and $\mathrm{P}_{2} \mathrm{O}_{5}$ developed by professor Larry Hench [19]. It is commercially available in the form of Novamin ${ }^{\mathrm{TM}}$ consisting of calcium sodium phosphosilicate.

When microscopic particles of Novamin ${ }^{\mathrm{TM}}$ are exposed to saliva, they release mineral ions forming hydroxycarbonate apatite, the chief mineral constituent of teeth [20]. Novamin ${ }^{\mathrm{TM}}$ can kill upto $99.9 \%$ of pathogens associated with caries [21,22].

3.4 Clinpro Tooth Creme ${ }^{\mathrm{TM}}$ is a commercially available organically modified tricalcium phosphate which can coexist with fluoride in aqueous environment. During brushing, this toothpaste contacts saliva and thereby calcium, phosphate and fluoride ions become readily available to tooth thus preventing demineralization [23]. 


\section{Sugar Substitute}

Xylitol is a naturally occurring pentilol which is a sugar substitute incorporated in chewing gums. Manton et al. showed that remineralization can occur with the use of sugar-free gum containing xylitol [24].

Xylitol acts by [25]:

- Reducing plaque formation

- Making plaque less adhesive

- Neutralize plaque acids by decreasing the production of lactic acid

- Reducing the levels of streptococcus mutans

- Increasing the salivary flow [26].

\section{Ozone}

Ozone is a chemical compound which is a powerful oxidizing agent. Ozone acts by attacking thiol groups of cysteine amino acid and destroys the cellular membrane of carious bacteria [27]. Ozone can shift microbial flora from acidogenic and aciduric micro-organisms to normal commensals allowing remineralization to occur [28].

Presently HealOzone (KaVo GmbH , Germany) remineralizing solution consisting of xylitol, fluoride, calcium, phosphate and zinc is approved for treatment of caries. It can be used as $2100 \mathrm{ppm}$ of ozone $\pm 5 \%$ at a flow rate of $615 \mathrm{cc} / \mathrm{min}$ for 40 seconds [29].

\section{Conclusion}

Prevention of dental caries by remineralization is a whole concept and philosophy focussing on intervention at the earliest possible stage with long term protection of the patient as a whole entity.

\section{References}

[1] Arathi Rao and Neeraj Malhotra, The Role of Remineralizing agents in Dentistry: A Review. Compendium ,July/Aug 2011 ,27-33.

[2] Winston AE, Bhaskar SN. Caries Prevention in the $21^{\text {ST }}$ century, J Am Dent Assoc, 129,1998, $1579-87$.

[3] J.D.B.Featherstone, "Dental caries is a dynamic disease process," Australian Dental Journal, 53(3), 2008,286-291.

[4] Louis Brearley Messer, The Current Status of Cariology ,Operative Dentistry, 3, 1978,60-65.

[5] Niessen LC, Gibson G, Oral health for a lifetime : preventive strategies for older adult, Quintessence Int., 28(9), 1997,626-630.

[6] Gordon Nikiforuk, Understanding Dental Caries, Vol 2: Prevention, Basic and Clinical Aspects (Basel: NewYork : Karger ,1985).

[7] Melgerg JR, Englander HR, Nicholson CR, Acquisition of fluoride in vivo by deciduous enamel from daily topical sodium fluoride applications over 21 months, Archives of Oral Biology, 12(10), 1967, 1139-1148.

[8] Hatibovic- Kofman S, Koch G. Fluoride release from glass ionomer cement in vivo and in vitro, Swed Dent. J, 15(6), 1991,253-258.

[9] GRO Wesenberg, E Hals. The in vitro effect of glass ionomer cement on dentine and enamel walls, Journal of oral rehabilitation, 7(1), 1980, 35-42.

[10] Benelli EM, Serra MC, Rodrigues AL Jr, Cury JA, In situ anticariogenic potential of glass ionomer cement, Caries Res ,27(4), 1993, 280-284.

[11] Seppa L, Korhonen A, Nurtinen A. Inhibitory effect on S.Mutans by fluoride treated conventional and resin-reinforced glass ionomer cements. Eur J Oral Sci.,103(3), 1995,182-185.

[12] Gao N, Smales RJ, Gale MS. Fluoride release/uptake from newer glass ionomer cements used with ART approach, Am J. Dent, 13,2000, 201-204.

[13] Rothwell M, Anstice HM, Pearson GJ. The uptake and release of fluoride by ion- leaching cements after exposure to toothpaste , $J$. Dent., 26, 1998; 591-597.

[14] Ruse ND, What is a "compomer"? J Can Dent Assoc.,65(9), 1999, 500-504.

[15] Ikemura K, Tay FR, Endo T, Pashley DH. A review of chemical-approach and ultramorphological studies on the development of fluoride-releasing dental adhesives comprising new prereacted glass ionomer (PRG) fillers. Dent Mater J, 27(3), 2008 May, 315339.

[16] Itota T, Carrick TE, Yoshiyama M, McCabe JF, Fluoride release and recharge in giomer, compomer and resin composite., Dent Mater. 20(9),2004, 789-795.

[17] Kouzmina E, Smirnova T, Pazdnikova N, A one-year clinical study of efficacy of a pit-and-fissure sealant containing bioactive glass, Oral Health and Dental Management in the Black Sea Countries, 8(1), 2009, 7-12.

[18] Calcium phosphate based remineralization systems: Scientific evidence? E.C.Reynolds,. Australian Dental Journal , 53, 2008, 268273.

[19] Bassett DC, Meszaros R., Orzol.D, Woy M, Ling Zhang Y.Tiedemann K, Wondraczed L, Komarova S, Barralet JE., Anew class of bioactive glasses : Calcium-magnesium sulfophosphates, J. Biomed Mater Res 2013 :25. doi : 10.1002/jbm.a.34955.

[20] Burwell AK, Muscle D. Sustained Calcium ion and $\mathrm{pH}$ release from calcium phosphate containing dentrifices, Paper presented at IADR/AADR/CADR $87^{\text {TH }}$ General Session and Exhibition; April 3, 2009; Miami, FL.

[21] Earl JS, Topping N, Elle J, Langford RM, Greenspan DC, Physical and chemical characterisation of the surface layers formed on dentin following treatment with a fluoridated toothpaste containing Novamin. J Clin. Dent, 22,2011: 68-73.

[22] Layer TM, Development of a fluoridated ,daily use toothpaste containing Novamin technologyfor treatment of dentin hypersensitivity, J. Clin Dent, 22, 2011,59-61.

[23] Gemimaa Hemagaran, Prasanna Neelakantan, Remineralization of tooth structure - The future of dentistry, International Journal of Pharm. Tech Research. 6(2), Apr-Jun 2014,487-493.

[24] Manton DJ, Walker GD, Cai F, Cochrane NJ, Shen P, Reynolds EC, Remineralization of enamel subsurface lesions in situ by the use of three commercially available sugar-free gums, Int. J. Paediatr. Dent., 18(4), 2008,284-90.

[25] Makinen KK, Can the pentilol-hexitol theory explain the clinical observations made with xylitol ? Med Hypotheses ,54, 2000, 603-13. 
[26] Gary H Hildebrandt, Brandon S.Sparks. Maintaining mutans streptococcus suppression with xylitol chewing gum, JADA, 131,2000 , 909-916.

[27] Baysan A, Beighton D, Assessment of ozone mediated killing of bacteria in infected dentine associated with non-cavitated occlusal carious lesions, Caries Res., 41,2007, 337-41.

[28] Baysan A, Lynch E, The use of ozone in dentistry and medicine, Prim Dent Care ,12(2), 2005, 47-52.

[29] Brazzelli M, Mckenzie L. Fieldings, Fraser C, Clarkson J, Kilonzo M, Waugh N. ,Systematic review of effectiveness and cost effectiveness of HealOzone for the treatment of occlusal pit/fissure caries and root caries, Health Technol Assess. iii-iv, ix-80. 